\title{
Tactile Maps and New Technologies for Blind and People with Visual Impairments
}

\author{
Maria I. Gkanidi, Athanasios S. Drigas
}

\begin{abstract}
Until recently, the medical model of disability has dominated, but times and views change so that the model of social inclusion is now the guideline. It is therefore the broad acceptance of the social model of disability that leads to these changes and assistive technology is the main tool that allows social inclusion. In this paper an attempt is made to investigate greek and international bibliography regarding the design, the use and the effectiveness of haptic maps. This bibliographic research is divided into two main parts, each of whom divided into sub-chapters. The first part includes definitions and researches related to the structure, form and operation of the tactile maps and, more generally, of the individual characteristics taken into account in their creation. In the second part, there is a brief presentation of the new technologies for the blind and visually impaired people.
\end{abstract}

Keywords: Tactile maps, New technologies, Visual impairment, Blindness, Design and use of tactile maps, ICTs

\section{INTRODUCTION}

A ccording to scientific terminology, an eye is defined as blind when it is unable to perceive light (darkening). A blind person is formally defined in the UK as a person whose eyesight renders him incapable of performing any task upon completion of which his sight is a sine qua non condition. The aforementioned condition usually refers to a visual acuity of $1 / 20$ or less in the best eye after correction.

Attempts to determine blindness often include visual field assessment. This term refers to the extent of the surroundings within which a person is able to see while holding his head still. In case of loss of visual field, even a person with visual acuity greater than $1 / 20$ can be considered blind. Significant visual impairment may occur when visual acuity is better than $1 / 20$ and worse than $1 / 3$. Partial vision (low vision, reduced vision) is considered when the visual acuity is between $1 / 20$ and $1 / 10$ [3].

\section{BEHAVIORAL AND NEUROLOGICAL RELATIONS OF MAP USE WITH EMPHASIS ON TACTILE MAP}

$\mathrm{I}_{\mathrm{n}}$ n the research of Lobben, Lawrence and Pickett (2014)

Manuscript received on April 17, 2021.

Revised Manuscript received on April 15, 2021.

Manuscript published on April 30, 2021.

*Correspondence Author

Maria I. Gkanidi*, Department of Primary Education, National and Kapodistrian University of Athens, Greece.

Athanasios Drigas, Research Director at N.C.S.R. 'Demokritos', Institute of Informatics and Telecommunications, 153 10, Athens, Greece. E-mail: dr@iit.demokritos.gr

(C) The Authors. Published by Blue Eyes Intelligence Engineering and Sciences Publication (BEIESP). This is an open access article under the CC BY-NC-ND license (http://creativecommons.org/licenses/by-nc-nd/4.0/) participants were asked to complete a test that included different types of graphics (simple geometry, complex geometry, text maps and text maps). Brain activation result

reveal that participants use maps differently than they use geometric objects.

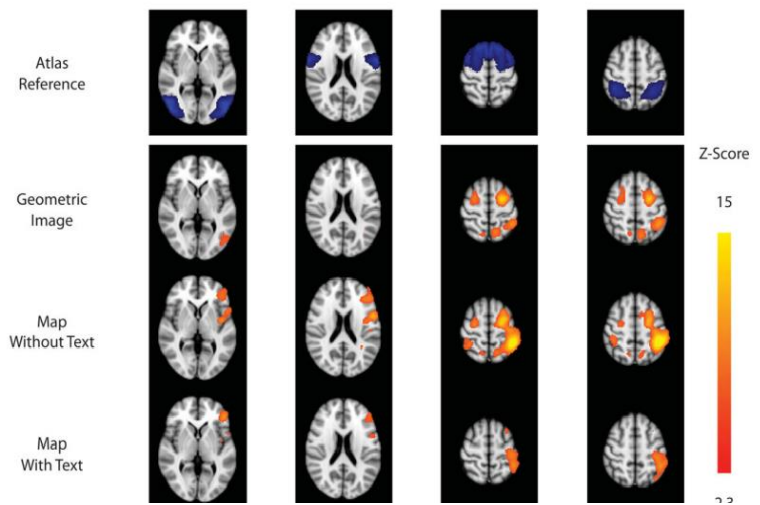

Picture 1 Types of maps selected for the experiment and the different areas of the brain affected by each one

(Lobben, Lawrence, \& Pickett, 2014)

Experiments tend to confirm the view that blind people have the same cognitive spatial abilities as people without visual impairment, but that their formative knowledge is less complex due to different access to information and past experiences [1], [2], [29], [30].

\section{TYPES OF TACTILE MAPS}

$\mathrm{T}$ maps and general reference maps. Mobility maps focus on information about navigating a specific area and are characterized by high identification accuracy. Orientation maps contain larger areas than mobility maps, give general information and are aimed mainly at groups of people. Finally, general reference tactile maps contain general information of mainly educational interest and are similar to conventional political and geophysical maps [3].

\section{A.Suitability of material for tactile maps}

According to the data collected in the Lawrence \& Lobben study (2011), the most appropriate material is based solely on personal preference.

All participants agreed that both maps had a high degree of readability, however most participants chose the microcapsule tactile map rather than the embossed tactile map [4].

Published By:

Blue Eyes Intelligence Engineering \& Sciences Publication

(C) Copyright: All rights reserved. 
Those characteristics that result in a high degree of readability and efficiency in the production and use of tactile maps were also identified. As it turned out the material of the maps is a matter of personal preference and tactile maps should be available to students in a variety of formats to meet individual needs [5], [6].

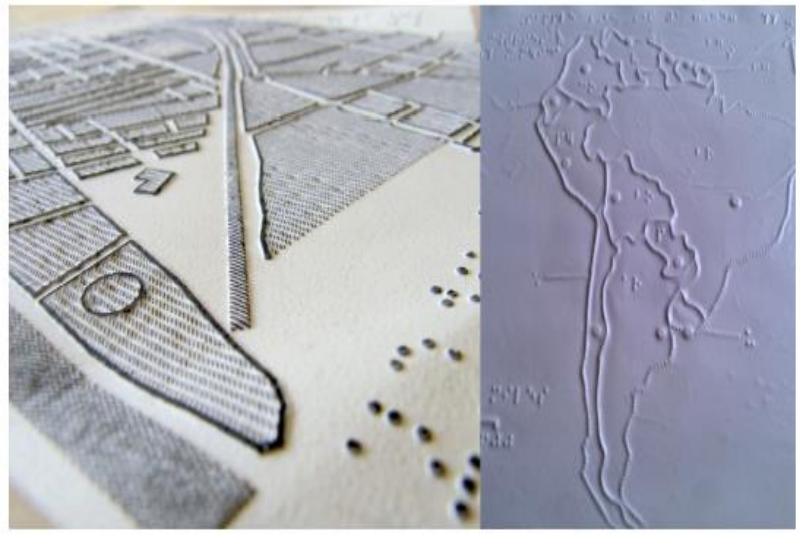

Picture 2 Microcapsule tactile map on the left and an embossed tactile map on the right (Gual, Puyuelo, \& Lloveras, 2015)

\section{B. Symbols}

A recent study of a tactile map experiment for the visually impaired tested a tactile map produced with 3D printing that included a new type of tactile symbol, the volumetric symbols (3D). These symbols are detected faster than conventional level symbols, with the same error rate, and are considered an improvement in the use of touch devices.

The study by Gual, Puyuelo and Lloveras (2015) analyzes the effect of including volumetric or 3D symbols on a plain map. To do this, the researchers compared two tactile maps. One of them uses only two-dimensional elements and is produced by thermoforming, one of the most popular systems in this field, while the other includes volumetric symbols, thus highlighting the possibilities that open up through 3D printing, a new production area. The results of the study show that the integration of 3D symbols improves the efficiency and autonomous use of these products [5].

\section{Tactile Inkjet Mapping Project}

In the Tactile Inkjet Mapping Project, an attempt was made to provide a new orientation regarding the simple design of the touch map through a rigorous experimental research on design issues. The first study evaluates the use of different materials for touch graphics. The second study examines the minimum noticeable distance between two lines. The third study investigates the optimal height (height from the paper) regarding the graphics produced.

Both groups of preferences searched faster on harder substrates. It is therefore possible to conclude that harder substrates, especially raw paper and microcapsule paper, allow faster and easier scanning.

The second study investigated the minimum separation distance between two elements of a double line. According to the results, two lines separated by at least $1.3 \mathrm{~mm}$ are perceived as double lines.

Finally, the features can be reliably identified on a simple map with magnifications of just 200 micro (0.2 mm) [4], [7].

\section{A. An e-integration system for the visually impaired people}

It is about a complex system for the visually impaired which uses alternative access methods, so that the disabled person has easy access to the Internet and therefore to information [8].

\section{B. Optical Character Recognition (OCR)}

Optical Character Recognition, commonly defined by the acronym OCR, is the process of recognizing and automatically converting existing characters in the written support image to text format, which can be then used in a variety of applications. OCR has been extensively studied and has made significant progress in terms of performance and accuracy of results obtained [9].

\section{Text-to-speech (TTS)}

The voice composition, defined as TTS (acronym for text-to-speech), is based on software that should be able to read any text, regardless of its source. TTS is based on the artificial human voice. Voice synthesis is a complex process as algorithms are required to produce an understandable and natural result [10].

Applications based on the above software are SayText, the e-book reader, Talking Camera Pro, to Prizmo Escaneamento, OCR \& Fala, LookTel, GroZi, ShopTalk, VizWiz, Universal Real-Time Navigational Assistance (URNA) [10], [11], [12], [13], [27].

\section{Interactive multimedia tactile maps}

These web maps add audio and voice commentary (text tags read by a screen reader) and tactile features, extending the usability and content richness of the raised ink. One such example is the Iqaluit sound map [14].

\section{E.Smart Vision Project}

The main goal of the SmartVision Project is to enable the autonomous navigation of people with disabilities in two different environments: internally and externally. The technologies used in this project are computer vision using a stereo system. In addition, RFID tags were added to minimize position errors as well as the use of GPS, for outdoor placement as well as location with three-way access point signals (Aps) [15].

\section{F. Tyflos}

This work presents the navigation methodology used by an intelligent assistant named Tyflos, able to help a visually impaired user be partially independent and able to walk and work in a dynamic 3D environment [16].

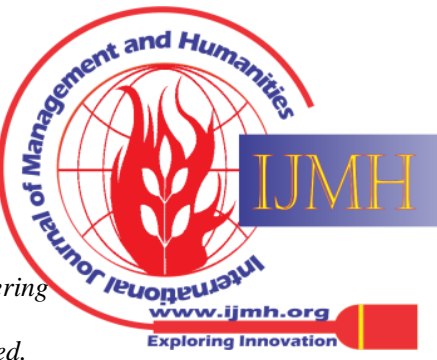




\section{G. NavCog}

NavCog is a new smartphone navigation system for the visually impaired or blind, capable of assisting users in autonomous mobility in complex and unfamiliar indoor / outdoor environments [17].

\section{H. Navigation system with binoculars and waist belt}

This system, which consists of binoculars and a waist belt, is able to detect obstacles around the subject up to 500 $\mathrm{cm}$ in front, left and right, using a network of ultrasonic sensors. It thus effectively calculates the distance of the detected object from the subject and prepares it so as to avoid obstacles. Voice instructions are also used to let the subject know about the detected obstacle and its distance [18].

\section{Autonomous driving}

A barrier avoidance system for the blind based on a hardware platform, used in the automotive industry [20].

\section{J. VoiceOver}

VoiceOver is a gesture-based screen reader which integrates with iOS software. VoiceOver allows visually impaired people to navigate themselves at the same time they are also typing and entering text [19].

\section{K. Bus tracking system}

It is the detection system that uses RFID technology and aims to facilitate the movement of the blind [21].

\section{SmartBo, a "smart apartment" for people with disabilities}

The SmartBo is a two-room ground floor apartment in a five-storey building located in a Stockholm suburb. This house along with seven others was built to serve as a cooperative housing for the elderly. As a result, entry is easy for the disabled beacause there are no stairs and the front door can be opened remotely [22].

\section{VibroGlove}

The device is an aid for reading the facial expressions of a person by people who are blind or visually impaired [23].

\section{N. Blind Hero a video game for the blind}

Music / rhythm games are especially suitable for this group of people, as they are perfectly capable of perceiving sound signals. Based on the popular Guitar Hero, a custom glove was made that players must use in order to be able to play the game [24].

\section{O. Software for creating tactile graphs}

Tactile graphs are considered more appropriate so that blind people can quickly and correctly understand the relationship between two corresponding variables [28].

\section{P. 3D printable tactile images (3DP-ATPs)}

The design of 3D printable tactile images (3DP-ATPs) for visually impaired young children has the potential to significantly increase the supply of tactile materials that can be used to support the emerging development of literacy skills [25].

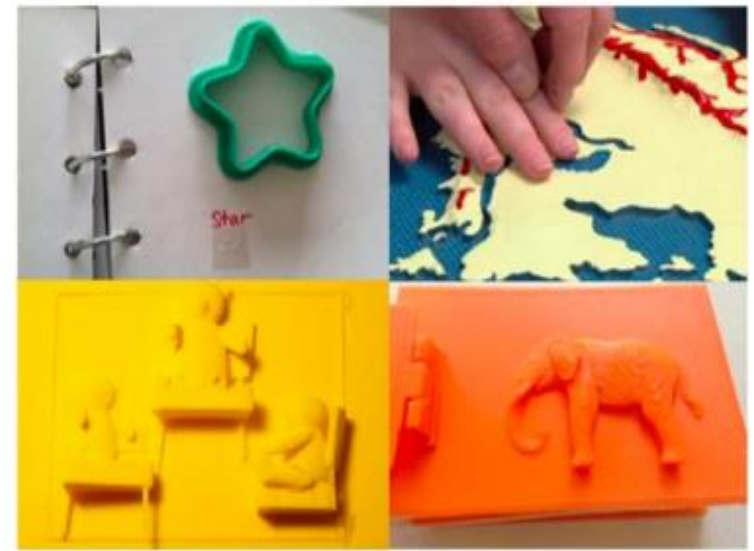

Picture 3 On top constructions by hand 2.5D-ATP/ATG (Source: Perkins School)

At the bottom 3D Printed 3DP-ATP (Stangl, Hsu, \& Yeh, 2015)

Q. 3D Printing technology for accessibility in buildings: the tactile map of the MTE Museum in Pavia

This is a tactile map for the blind and visually impaired by the Museum of Electrical Engineering of the University of Pavia (Italy). The tactile map represents the building plan with all the information that guides a visitor. The device is the result of a research process that is carried out with various steps and experimental tests, in order to determine the best 3D printing profiles to meet all the requirements of end users [26].

\section{CONCLUSIONS}

Theories that have been developed regarding tactile maps are based on the cognitive, neurological and behavioral model, testifying their multidimensional and dynamic nature. None of the models provide absolute knowledge, on the contrary, they overlap.

In order to achieve movement from one point to another, even more important than knowing the routes, is the orientation to the environment. For this purpose, the conquest of the mental map is required. It is therefore important that these maps take into account the particular characteristics of the individuals for whom they are intended. This also implies that the blind or visually impaired person can locate the path by reconstructing the space mentally.

As it turns out, there is no universally accepted method of producing tactile maps by the scientific community. There are, however, some conventions followed by several cartographers such as the size of the lines or the choice of rougher texture.Tactile cartography follows the evolution of technology, as 3D printing is gaining ground over 2D printing. Technology facilitated these individuals by utilizing most of their senses, especially the sense of touch and hearing, providing them holistic help.

Published By:

Blue Eyes Intelligence Engineering

\& Sciences Publication

(C) Copyright: All rights reserved. 
Research has also shown that there are preferences in design, symbolism, features and cartography. Tactile maps should be easy to read by touch and provide useful information without confusing users. The symbols should be simple and easy to remember. In other words, it is important to create touch maps and models that are "user friendly".

The touch map should be realistic (eg, sidewalks should be higher than roads, the texture of the roads should be rougher than the texture of the sidewalks). It is good to use durable materials, which will not be easily damaged by repeated use of the map.

When using braille inscriptions, it is better to write them in the same direction (eg, on the map, parallel to the actual road). A touch map should have a signature. Finally, the objects on the model should have the right proportions between them, based on the actual objects so that a user will be able to move around the city without the risk of being disoriented and lost.

Tactile maps enable the user to form new mental maps or to update and supplement existing ones from other cognitive functions. Assistive technology is a field of knowledge (interdisciplinary) that includes the development of products, resources, methodologies, strategies, practices and services aimed at promoting the functionality, activity and participation of people with disabilities in order to improve autonomy, quality of life, facilitate thus their social integration.

New technologies are the essential element for the social integration of blind and visually impaired people. The plethora of technological tools and software, the audiovisual tactile maps and augmented reality maps, are a promising course in this direction. A key future question for researchers should be how all this developing technology will be able to evolve and be utilized as best as possible, both individually and collectively, facilitating the lives of these individuals.

\section{REFERENCES}

1. Lobben, A., Lawrence, M., \& Pickett, R. (2014). The map effect. Annals of the Association of American Geographers, 104(1), 96-113

2. Perkins, C. (2002). Cartography: progress in tactile mapping. Progress in Human Geography, 26(4), 521530.doi:10.1191/0309132502ph383pr

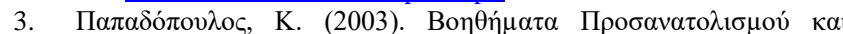

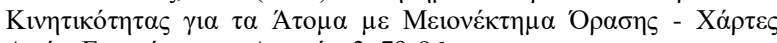

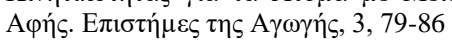

4. Lawrence, M. \& Lobben, A. (2011). The design of tactile thematic symbols. Journal of Visual Impairment and Blindness, 105(10), 681691

5. Gual, J., Puyuelo, M., \& Lloveras, J. (2013). Improving Tactile Map Usability through 3D Printing Techniques: An Experiment with New Tactile Symbols. The Cartographic Journal, 52(1), 51-57. doi:10.1179/1743277413y.0000000046

6. Gual, J., Puyuelo, M., \& Lloveras, J. (2015). The effect of volumetric (3D) tactile symbols within inclusive tactile maps. Applied Ergonomics, 48, 1-10. doi:10.1016/j.apergo.2014.10.018

7. Jehoel, S., McCallum, D., Rowell, J., \& Ungar, S. (2006).An empirical approach on the design of tactile maps and diagrams: The cognitive tactualization approach. British Journal of Visual Impairment, 24(2), 67-75.doi:10.1177/0264619606063402

8. Drigas, A. S., Koukianakis, L. G., \& Papagerasimou, Y. V. (2005) A system for e-inclusion for individuals with sight disabilities, Mathematical methods and computational techniques in electrical engineering, 146-150

9. Neto, R. \& Fonseca, N. (2014). Camera reading for blind people. Procedia Technology, 16 , 1200-1209

10. Bigham J. P., Jayant C., Miller A., White B., \& Yeh T., (2010).
"VizWiz::LocateIt - enabling blind people to locate objects in their environment," IEEE Conf. Comput. Vis. Pattern Recognition Workshops (CVPRW), 65-72.

11. Kulkarni, A., \& Bhurchandi, K. (2015). Low cost E-book reading device for blind people, IEEE international conference on computing communication control and automation (ICCUBEA), 516-520

12. J. P. Bigham, C. Jayant, H. Ji, G. Little, A. Miller, R. C. Miller, R. Miller, A. Tatarowicz, B. White, S. White, and T. Yeh. VizWiz: Nearly Real-time Answers to Visual Questions. In User Interface Software and Technology, 2010.

13. Kulyukin, V., Gharpure, C., \& Nicholson, J. (2005). RoboCart: toward robot-assisted navigation of grocery stores by the visually impaired. In Proceedings of the IEEE/RSJ International Conference on Intelligent Robots and Systems, Alberta, Canada

14. Siekierska, E., LaBelle, R., Brunet, L., McCurdy, B. Pulsifer, P., Rieger, M. K., \& O’Neil L. (2003). Enhancing spatial learning and mobility training of visually impaired people: a technical paper on the Internet-based tactile and audio-tactile mapping. The Canadian Geographer, 47(4), 480-493. doi: 10.1111/j.0008 3658.2003.00037.x

15. Faria, J., Lopes, S., Fernandes, H., \& Martins, P. B. (2010). Electronic white cane for blind people navigation assistance, World Automation Congress, 1-7

16. Bourbakis, N. G., \& Kavraki, D., (2001). An intelligent assistant for navigation of visually impaired people. In Proceedings of the 2nd Annual IEEE International Symposium on Bioinformatics and Bioengineering, 230-235

17. Ahmetovic D., Gleason C., Kitani K., Takagi H., \& Asakawa C., (2016) NavCog: Turn-by-turn smartphone navigation assistant for people with visual impairments or blindness. In Proceedings of the 13th Web for All Conference, 91-92

18. Cattaneo, Z. \& Vecchi, T. (2011). Blind vision: the neuroscience of visual impairment. Cambridge: MIT Press.CrossRef

19. Kyudong, P ., Taedong, G., \& Hyo-Jeong, S. (2015). Toward accessible mobile application design: developing mobile application accessibility guidelines for people with visual impairment. Proceedings of HCI Korea, 31-38.

20. Martinez, M., Roitberg, A., Koester D., Schauerte, B. \& Stiefelhagen, R. (2017). Using Technology Developed for Autonomous Cars to Help Navigate Blind People, IEEE International Conference on Computer Vision Workshops (ICCVW), $1424-1432$

21. Kalbani, J. Al., Suwailam R. B., Yafai A. Al., Abri, D. Al., \& Awadalla M. (2015). Bus detection system for blind people using RFID, IEEE 8th GCC Conference \& Exhibition, 1-6

22. Elger, G., \& Furugren, B., (1998) SmartBO an ICT and computer based demonstration home for disabled, Improving the quality of life for the European citizen Technology for Inclusive Design and Equality Assistive Technology Research Series, 4, 392-395

23. Krishna, S., Bala, S., McDaniel, T., McGuire, S., \& Panchanathan, S. (2010). VibroGlove. Proceedings of the 28th of the International Conference Extended Abstracts on Human Factors in Computing Systems. doi:10.1145/1753846.1754031

24. Yuan, B. \& Folmer, E. (2008). Blind hero. Proceedings of the 10th International ACM SIGACCESS Conference on Computers and Accessibility - Assets '08. doi:10.1145/1414471.1414503

25. Stangl, A., Hsu, C.-L., \& Yeh, T. (2015). Transcribing Across the Senses. Proceedings of the 17th International ACM SIGACCESS Conference on Computers \& Accessibility - ASSETS '15. doi:10.1145/2700648.2809854

26. Auricchio, F., Greco, A., Alaimo, G., Giacometti, V., Marconi, S., \& Mauri, V. (2017). 3D printing technology for buildings accessibility: the tactile map for MTE museum in Pavia, Journal of Civil Engineering and Architecture, 11, 736-747.

27. Bohonos, S., Lee, A., Malik, A., Thai, C., \& Manduchi, R. (2007). Universal real-time navigational assistance (URNA) Proceedings of the 1st ACM SIGMOBILE International Workshop on Systems and Networking Support for Healthcare and Assisted Living Environments - HealthNet '07.doi:10.1145/1248054.1248080

28. Watanabe, T., Yamaguchi, T. \& Nakagawa, M.( 2012). Development of software for automatic creation of embossed graphs. In International Conference on Computers for Handicapped Persons, 174-181

Blue Eyes Intelligence Engineering

\& Sciences Publication

(C) Copyright: All rights reserved.

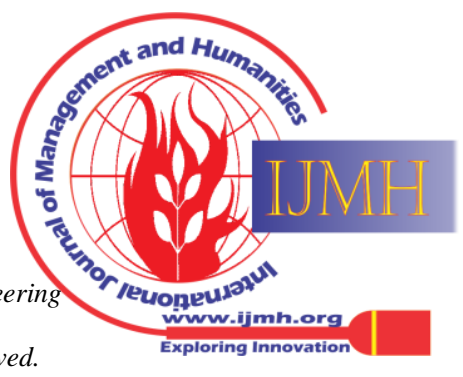


29. Tinti, C., Adenzato, M., Tamietto, M., Cornoldi, C., 2006. Visual experience is not necessary for efficient survey spatial cognition: evidence from blindness. Q. J. Exp. Psychol. 59, 1306-1328.

30. Vecchi, T., Tinti, C., Cornoldi, C., 2004. Spatial memory and integration processes in congenital blindness. Neuroreport 15, 2787 2790 .

\section{AUTHORS PROFILE}

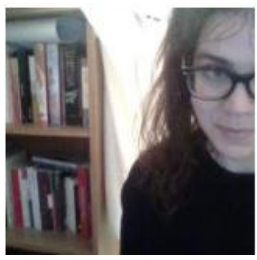

Maria I. Gkanidi, is a graduate of National and Kapodistrian University of Athens department of

Primary Education. She has a Msc in Educational Technology and Human Resources Development, National and Kapodistrian University of Athens department of Primary Education in association with the Piraeus University of applied Sciences, department of Business and Administration and another post degree in Specialisation on ICT and Special Education-Psychopedagogy of integration, N.C.S.R. "Demokritos" in association with the department of Greek Philology at Democritus University of Thrace. She was also speaker in two experiential workshops on " Art inspires teaching " and "First world war and art " at Marasleios Academy, Athens.

She currently works as a primary education teacher.

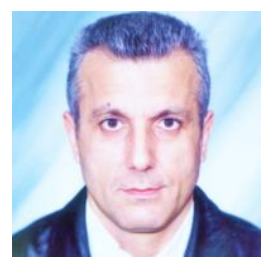

Athanasios Drigas, is a Research Director at N.C.S.R. 'Demokritos', Institute of Informatics and Telecommunications, 153 10, Athens, Greece. He is the Coordinator of Net Media Lab \& MindBrain R\&D. He has Coordinated Several International Projects, in the fields of Cognition and e-services (e-psychology, e-inclusion, elearning, e-government, e-culture etc.). He has published more than 320 articles, 7 books, 25 educational CD-ROMs and several patents. E-mail: $\underline{\text { dr@iit.demokritos.gr). }}$

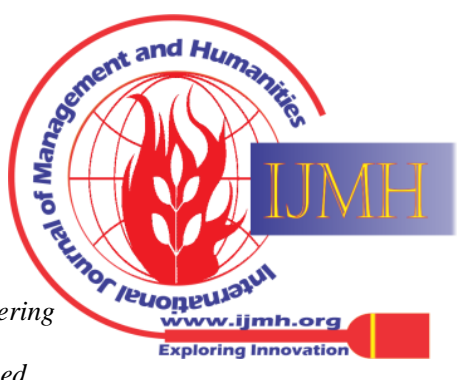

